\title{
Hol: THE AUSTIN WING OF THE CAVENDISH LABORATORY
}

\author{
By SIR LAWRENCE BRAGG, O.B.E., F.R.S.
}

TN May 1936 the late L Jd Austin sent the following letter to the Chancellor of the University of Cambridge :

"Dear Mr. ph LDWrn,

"I have for several years been watching the very valuakeryork done by Lord Rutherford and his colleages at Cambridge in the realm of scientific research, and knowing that as Chancellor you are keenly interested in obtaining sufficient funds to build, equip, and endow a very much-needed addition to the present resources, I shall be very pleased indeed to present securities to the value of approximately $£ 250,000$ for this purpose.

Yours sincerely,

$$
\text { H. Austin." }
$$

Of this munificent gift, a sum of $£ 37,000$ was at once applied to building and equipping a high-tension laboratory and installing a cyclotron. A further sum of $£ 100,000$ was set apart as a building fund ; $£ 80,000$ for a new wing of the Laboratory and $£ 20,000$ for alterations to the existing Cavendish block. The residue provides an annual income for the general research of the Laboratory.

The plans for the new wing were completed before Lord Rutherford's death; but the actual building was not started until May 1938. Though many in the Laboratory had a part in the designs, the main responsibility for the plans rested upon Prof. J. D. Cockcroft. Building had not progressed very far at the outbreak of war, and at one time it appeared that work on it might have to stop. We were able to proceed, however, by giving. an undertaking that accommodation would be found in the Laboratory for Service research departments if need should arise.
Lord Austin laid the foundation stone in May 1939, and the building was completed by June 1940 . It was at once occupied by the Admiralty Signal School and the Ballisties Directorate, Research Department, Woolwich, both of which had been driven from their homes by air attacks. Towards the end of the War, some sections of the building were handed back to the Laboratory, but we were not able to occupy the whole until January 1945. It had then to be decorated, furnished and provided with apparatus and machine tools; it is now in full running order. The new wing was formally opened by Sir John Anderson on July 24 of this year, during the international physics conference arranged jointly by the Physical Society and the Cavendish Laboratory.

The architect, Mr. C. Holden, assisted by Mr. H. G. Cherry, designed for us a building which is very simple in plan, and at the same time is attractive and very convenient. It is $115 \mathrm{ft}$. in length by $45 \mathrm{ft}$ : in width, and $55 \mathrm{ft}$. in height. Each of the four floors and the basement are of similar design, with rooms of standard size or multiples of this size on either side of a central corridor $8 \mathrm{ft}$. wide and $13 \mathrm{ft}$. high running the whole length of the building. The standard research room is $15 \mathrm{ft}$. by $17 \mathrm{ft}$., with two windows. The outer walls and walls of the corridor carry the strong concrete floors, on which rest light walls separating the research rooms, so that it is a simple matter to subdivide a room or to remove a dividing wall. There are also removable panels above the doors, and with so high and wide a corridor it is possible to move quite large units of apparatus into any room. The area occupied by the building is $9,000 \mathrm{sq}$. ft., and the total floorspace 34,000 sq. ft.

In planning the services to the rooms, flexibility was aimed at rather than a complete provision for all possible needs. "The services come up a shaft next the liftshaft, run along the sides of the corridors above the doors on open battens, and then enter the research rooms, so that it is easy to alter or add to them. The standard supplies of gas, water, electricity and compressed air are distributed around the walls of the rooms above a narrow shelf which corresponds in height to the tables used for research, leaving the centre of each room quite free. The electrical supplies from the D.c. generators are available in any room, and can be controlled from it.

The second floor houses the administrative centre of the whole Laboratory. It has rooms for the senior teaching staff and the clerical staff. A large bay is used for the museum of historic apparatus, and on its walls are displayed the annual 


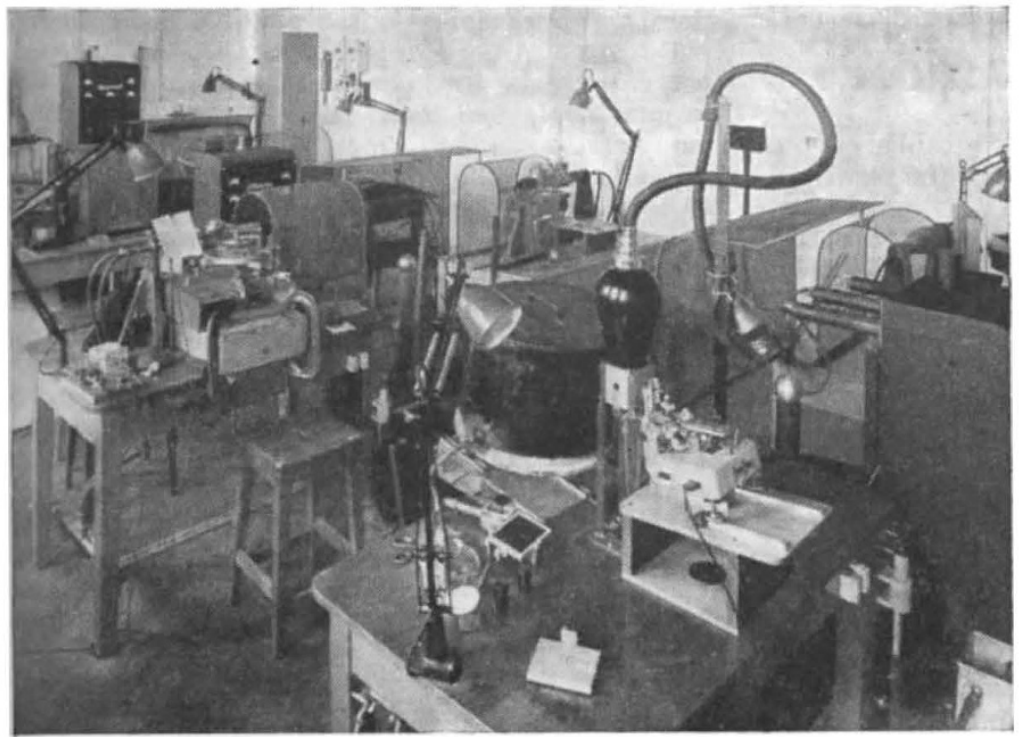

Fig. 2. A TYPICAL RESEAROH ROOM

shop, for packing and unpacking and for storing gear before it is assembled, would be a great boon, and it is not provided for in the present wing; which had to be planned on a restricted site. The amount of 'junk' carried by the Laboratory is also on a correspondingly large scale. It is a most important liquid asset, exceed. ingly useful for research purposes of all kinds. A large space should be set aside for it where it is easily accessible and can be classified, otherwise it clutters up valuable research rooms or the corridors. Another need is for many more small 'offices'. In former days a re. searcher, working with smallscale apparatus, could have a desk in the corner of his lab. oratory, where he kept his papers and did his calculations. Now that many research rooms resemble the interior of a power.

photographs of staff and research students, a remarkable series running from 1897 which has only been broken during the two World Wars. A large room on this floor with an attached pantry is used for the Cavendish 'teas' and other social gatherings, and for conferences and committer meetings. The library is also on the second floor. The style of the rest of the Laboratory is purely functional, but on this floor we have aimed at providing a fitting Laboratory centre. In designing the furniture and decorations we had the help of Mrs. Hubert Worthington. A colloquium room 'seating about seventy is on the first floor beneath the library.

Another group of rooms provides for the main workshop, steward's office, students' workshop, glassblower's rooms, general storeroom, and standards room. There is also a 'special techniques' workshop where delicate operations requiring the highest technical skill are carried out.

Of the ninety rooms in the building, thirty-one are research rooms of unit or multiple unit size, and thirteen are offices. Store-rooms, dark rooms, generator room, heating and other services, together with the special rooms mentioned above, account for the remainder. No part of the building is used for undergraduate teaching, though all students use the library.

Even with the most careful planning and foresight, certain needs only become apparent when a building comes into service. Much apparatus for physical research is now on an engineering scale. A large covered space near the work-

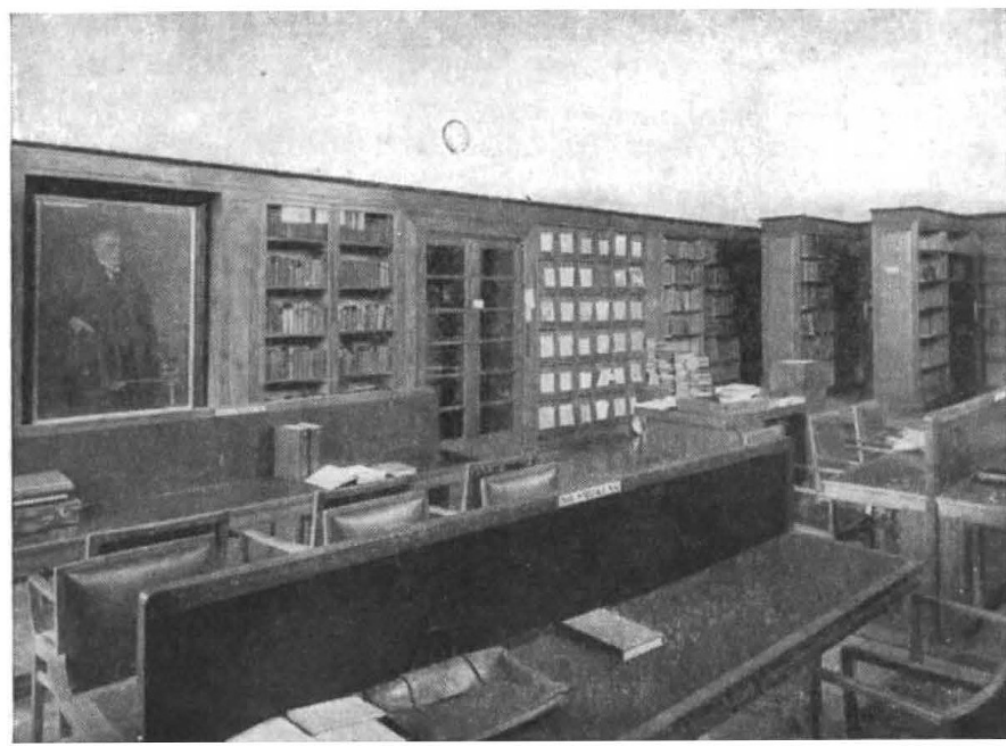

FIG. 3. LIBRARY station, this is no longer convenient. Researchers greatly value private cubicles, however small, where they can work or talk with their colleagues in quiet surroundings. I mention these needs because our experience may be of interest to others who are planning laboratory extensions. On the whole, the planning of the new wing has been highly successful, and the competition to work in its convenient and attractive research rooms is very keen.

The building cost $£ 77,000$, apparatus and equipment $£ 10,000$, furniture and fittings $£ 4,500$. We were indeed fortunate that it was built at the beginning of the War; quite apart from the cost, the same high standards will be impossible to attain for many years to come. 